ISSN: 2146-3042

DOI: $10.25095 /$ mufad.935545

\title{
Bütünleşik SD ve PROMETHEE ÇKKV Yöntemleri ile Portföy Optimizasyonu: BİST Gıda, İçecek ve Tütün Sektöründe Ampirik Bir Uygulama*
}

\author{
Osman Yavuz AKBULUT** \\ Zekai ŞENOL ${ }^{* * *}$
}

\begin{abstract}
ÖZET
Bu çalışmanın amacı, firma getirisini etkileyebilecek değişkenler ve Çok Kriterli Karar Verme (ÇKKV) tekniklerine göre optimal portföy oluşturmaktır. Çalışmada, BISST Gıda, Içecek ve Tütün sektöründe faaliyet gösteren firmaların 2015 2020 dönemine ilişkin verileri kullanılmıştır. Bu amaçla çalışmada Standard Deviation (SD) ve The Preference Ranking Organization Method for Enrichment Evaluation (PROMETHEE) ÇKKV yöntemlerinden oluşan bütünleşik bir model kullanılmıştır. Çalışmanın ilk aşamasında SD yöntemi kullanılarak, seçilen finansal kriterlere ilişsin ağırlık katsayıları tespit edilmiştir. SD yöntemine göre, tüm örneklem döneminde, firmaların performansı üzerinde etkili olan en önemli kriter cari orandır. İkinci aşamada PROMETHEE yöntemi ile firmaların performans skorları tespit edilmiştir. Son aşamada ise elde edilen performans skorlarına bağlı olarak PROMETHEE yöntemine göre etkin sinır üzerinde yer alan firmalardan bir portföy oluşturulmuştur. PROMETHEE yöntemi sonuçlarına göre çalışma kapsamına alınan tüm dönemlerde etkin sinır üzerinde yer alan 6 firmanın olduğu sonucuna ulaşılmıştır. Elde edilen sonuçlara göre, seçilen alternatiflere ve kriterleri bağlı olarak oluşturulan optimal portföyün sektör ve BiST-100 endeks getirisinden daha yüksek getiri sağladığı anlaşılmıştır. Bu nedenle, seçilen karar değişkenleri ve ÇKKV tekniklerinin optimal portföy oluşturmada tutarlı olduğu söylenebilir.
\end{abstract}

Anahtar Kelimeler: Portföy Optimizasyonu, Portföy Seçimi, SD, PROMETHEE, ÇKKV

JEL Sinıflandırması: C61, G11, G17

Portfolio Optimization with Integrated SD and PROMETHEE MCDM Methods: An Empiric Application in ISE The Food, Beverage and Tobacco Industry

\section{ABSTRACT}

The aim of this study is to create an optimal portfolio according to variables that can affect the firm's return and Multi-Criteria Decision Making (MCDM) techniques. In the study, the data of the companies operating in the ISE Food, Beverage and Tobacco sector for the period of 2015-2020 were used. For this purpose, an integrated model consisting of Standard Deviation (SD) and The Preference Ranking Organization Method for Enrichment Evaluation (PROMETHEE) MCDM methods was used in the study. In the first stage of the study, weighting coefficients for the selected financial criteria were determined using the SD method. According to the SD method, the most important criterion affecting the performance of firms in the whole sample period is the current ratio. In the second stage, the performance scores of the companies were determined with the PROMETHEE method. In the last stage, a portfolio was created from companies that are above the effective limit according to the PROMETHEE method, depending on the performance scores obtained. According to the results of the PROMETHEE method, it was concluded that there were 6 companies that were above the effective limit in all periods included in the study. According to the results obtained, it is understood that the optimal portfolio created depending on the selected alternatives and criteria provides a higher return than the sector and BIST-100 index return. Therefore, it can be said that the selected decision variables and MCDM techniques are consistent in optimal portfolio creation.

Keywords: Portfolio Optimization, Portfolio Selection, SD, PROMETHEE, MCDM

Jel Classification: C61, G11, G17

\footnotetext{
* Makale Gönderim Tarihi: 10.05.2021, Makale Kabul Tarihi: 03.08.2021, Makale Türü: Nicel Analiz

** Sivas Cumhuriyet Üniversitesi, Sosyal Bilimler Enstitüsü, Muhasebe, osmanyavuz_39@hotmail.com, ORCID: 0000-0001-9225-1728.

*** Doç. Dr., Sivas Cumhuriyet Üniversitesi, İktisadi ve İdari Bilimler Fakültesi, zsenol@cumhuriyet.edu.tr, ORCID: 0000-0001-8818-0752.
} 


\section{GíRiş}

Serbest piyasa ekonomilerinin hâkim olduğu günümüz dünyasında, finans piyasaları oldukça önemli işlevler üstlenmektedir. Finans piyasalarının üstlenmiş oldukları bu işlevlerden birisi de şüphesiz tasarruf sahiplerinin birikimlerini etkin bir şekilde yatırımlara yönlendirmektir (Biswas, 2015: 445). Ancak bu noktada tasarruf sahipleri ya da yatırımcıların yatırım yapacakları hedef veya politikalarını belirlemeleri gerekmektedir. Gerek firmaların gerekse de bireysel yatırımcıların karar verme süreçlerinde birden fazla alternatifle karşı karşıya kalabilmesi de oldukça sık rastlanan bir durumdur. Böyle bir durumda yatırımcıları en etkin ve en verimli sonuca ulaştıracak karar şüphesiz en fazla faydayı sağlayacak alternatifin seçilmesi kararıdır (Şahin ve Akkaya, 2013: 68). Söz konusu hedef ve politikaların belirlenmesinden sonra ise yatırımcılar, tasarruflarını yönlendirebilecekleri finansal varlıkların seçimi ile karşılaşmaktadırlar. Dolayısıyla bu seçim, yatırım kararlarındaki en kritik noktayı oluşturmaktadır (Kayalıdere ve Aktaş, 2008: 292). Yatırımcıların, belirlemiş oldukları hedef ve politikalar doğrultusunda tercih edecek oldukları finansal varlıklar ise genel olarak, pay senetleri, finansman bonoları, tahviller, altın ve gümüş gibi kıymetli madenler olarak ifade edilebilir.

Tasarruf sahipleri yapacak oldukları yatırımların kararlarını verebilmek için uygun yatırım ortamı ve uygun firsatları da belirlemek adına sıklıkla gerek teknik gerekse de temel analiz yöntemlerinden faydalanarak bir taraftan elde edecekleri getiri düzeyini maksimize etmeyi diğer taraftan ise katlanmak zorunda oldukları risk seviyelerini de minimize etmeyi amaçlamaktadırlar (Kartal, 2019:300, Bayramoğlu ve Yayalar,2017: 2). Amaçları kapsamında farklı piyasalardan farklı niteliklere sahip çok sayıda finansal varlık veya menkul kıymeti inceleyerek hem en kazançlı hem de en risksiz yatırım araçlarının tespiti ise yatırımcılar için en önemli sorun olmaktadır. Bu sorun ise finans literatüründe portföy seçim problemi ya da portföy optimizasyonu olarak isimlendirilmektedir (Grujić, 2015: 67).

Portföy seçimi herhangi bir portföye dahil edilecek varlıkların ya da menkul kıymetlerin tespit edilerek oluşturulan portföyün yönetilmesini ifade etmektedir. Portföye dahil edilecek menkul kıymetlerin seçimi ile ilgili olarak literatüre konu olan iki temel finans kuramı mevcuttur. Bunlardan ilki 1950'li yıllara kadar geçerli olan geleneksel portföy kuramı, portföy oluşturulurken farklı özelliklere sahip ve farklı sayılarda menkul kıymetin portföye dahil edilerek risk unsurunun azaltılabileceğini ve yatırımcıların bu vasitayla minimum risk ile maksimum getiri elde edebileceklerini varsaymaktadır. Ancak geleneksel portföy yönetim kuramının en büyük eksikliği portföye dahil edilen menkul kıymetler arasındaki korelasyonun dikkate alınmamasıdır (Markowitz, 1999: 5-6, Kartal, 2019: 300). İkinci finans kuramı olan ve 1952 yılında Harry Max Markowitz tarafından literatüre kazandırılan modern portföy kuramı ise portföy oluşturulurken portföye dahil edilecek menkul kıymet getirilerinin birbirleriyle olan ilişkisinin diğer bir ifade ile korelasyonlarının göz önünde bulundurulması gerektiğini ifade etmektedir. Modern portföy kuramına göre sadece portföye dahil edilecek menkul kıymetlerin çeşitlendirmesi yalnız başına risk unsurunu minimum seviyelere indirmek için yeterli olmayabilir bu sebeple portföye birbirleri ile zit yönlü veya düşük korelasyona sahip menkul kiymetlerin dahil edilerek belirli bir getiri seviyesinde risk unsuru azaltılabilmektedir (Markowitz, 1999:7, Söylemez ve Koç,2017:119). Dolayısıyla yatırımlarını risk ve getiri ölçeğinde yapan tasarruf sahiplerinin farklı risk ve getiri profiline sahip olduğu göz önünde bulundurulduğunda, maksimum düzeyde getiri elde edebilmek açısından oluşturulan portföylerin risk ve getirilerinin ölçülmesi de hayati bir önem taşıyan 
husus haline gelmektedir (Korkmaz ve Pekkaya, 2009: 507-509). Portföy üzerinde etkili olan riskleri ise genel olarak, sistematik (piyasa) ve sistematik olmayan (spesifik) riskler olarak ifade etmek mümkündür. Burada ifade edilen sistematik risk, ekonomik, politik, sosyal durum ve çevresel faktörlerin değişkenliği sebebiyle ortaya çıkabilen riskler olup çeşitlendirme ile elimine edilemeyen riskler olarak tanımlanırken, sistematik olmayan risk ise firmalar ya da firmaların faaliyet göstermiş oldukları sektörden kaynaklanan risklerden oluşmaktadır ve çeşitlendirme yoluyla elimine edilebilmektedir (Kartal, 2019: 301). Markowitz'in literatüre kazandırmış olduğu modern portföy kuramı ile getirdiği yenilik gerek matematiksel gerekse istatistiksel veriler yardımıyla portföyün oluşturulabileceği ve yine aynı veriler yardımıyla risk ve getirilerin ölçülebileceğidir (Grujić, 2015: 68). Söz konusu kurama göre portföyün riski portföyün standart sapması ve varyansı ile ölçülmektedir (Markowitz, 1999: 6). Markowitz tarafından tanımlanmış olan modern portföy kuramı ve ortalama varyans modeli sayesinde portföyün riskinin minimum seviyelere indirilebileceği ilk kez mantıklı bir temele oturtulmuştur. Söz konusu teoriye göre karar verici konumunda bulunan yatırımcılar, kendi aralarında negatif bir korelasyona sahip menkul kıymetleri portföye dahil ederek portföyün riskini düşürebileceklerdir (Pala ve Aksarayl1, 2017: 171, Arditti, 1971: 911, Konno vd., 1993: 94).

Optimal portföy seçimine veya diğer bir ifade ile portföy optimizasyonuna ilişkin literatürde yer alan çalışmalar incelendiğinde (Örneğin; Markowitz (1952), Roy (1952), Nielsen (1987, Demirtaş ve Güngör (2005), Küçükkocaoğlu (2002)) tarafindan yapılan çalışmaların genellikle Markowitz'in ortalama varyans modeli kapsamında ele alındığı açıkça görülmektedir. Ancak Markowitz modelinin çokça test edilmiş olması ve çeşitli bilim dallarında ortaya çıkarılan yeni teknikler, araştırmacıları farklı değişkenlerin dahil edilebildiği daha az veri seti ile hesaplamalara olanak tanıyan başarılı bir portföy oluşturabilme arayışına sevk etmiştir. Söz konusu tekniklerden biri olan Çok Kriterli Karar Verme (ÇKKV) teknikleri, değerlendirme kriterlerinin çeliştiği durumlarda oldukça kullanışlı ve etkin çözümler üretebilen teknikleri bünyesinde barındırmaktadır. Bu çerçevede Vetschera ve De Almeida (2012), Aksaraylı ve Pala (2016), Bouri vd., (2002), Marasovic ve Babic (2009), Şahin ve Akkaya (2013), Pala ve Aksaraylı (2017) çalışmalarında ÇKKV tekniklerinden PROMETHEE ile alternatif portföylerin sıralamalarını belirleyerek etkin sonuçlar elde etmişlerdir. Buna ilaveten yine ÇKKV tekniklerinden biri olan Veri Zarflama Analizi (VZA) ile de portföy seçimi üzerine yapılmış olan birçok çalışma (Örneğin; Murthi vd. (1997), Basso ve Funari (2001), Emel vd. (2003), Eilat vd. (2006), Edirisinghe ve Zhang, (2007), Chen (2008), Ahmadzade vd. (2011)) literatürde yer almaktadır. Ancak ÇKKV teknikleri ile yapılmış olan çalışmalar sadece bunlardan ibaret değildir. Literatür incelendiğinde PROMETHEE ve VZA yöntemlerinin haricinde daha birçok teknik kullanılarak portföy seçimine ilişkin çalışmaların yapıldı̆̆ı görülebilmektedir.

Dolayısıyla bu çalışmanın amacı ÇKKV tekniklerinden SD ve PROMETHEE teknikleri kapsamında BİST Gıda, İçecek ve Tütün Sektöründe faaliyet gösteren firmaların 2015-2020 zaman dönemini kapsayan finansal verilerini kullanarak pay senetlerinden oluşan bir optimal portföy oluşturmaktır. Çalışma, gerek optimal portföy seçimi hakkında yatırımcılara yeni ve özgün bir bütünleşik modelin (SD-PROMETHEE) önerilmesi ve önerilen modelinde ilk kez bu çalışmada test edilmesi gerekse de kullanılan veri setinin genişliği açısından oldukça özgün bir bakış açısına sahiptir. 
$\mathrm{Bu}$ çalışma beş bölümden meydana gelmektedir. Giriş bölümünün oluşturduğu ilk bölümün hemen ardından ikinci bölümde literatürde yer alan çalışmalar özetlenmiştir. Üçüncü bölümde metodoloji tanıtılmış olup dördüncü bölümde uygulama sonuçlarına yer verilmiştir. Son bölüm olan beşinci bölümde ise genel bir değerlendirme yapılarak çalışma sonlandırılmıştır.

\section{LITERATÜR İNCELEMESI}

Portföy seçimi veya portföy optimizasyonu üzerine daha önce yapılmış ve literatüre konu olan birçok ulusal ve uluslararası çalışma bulunmaktadır. $\mathrm{Bu}$ bölümde söz konusu çalışmalardan bazıları kronolojik olarak aşağıda özetlenecektir.

BİST Tekstil sektöründe faaliyet gösteren 21 firmanın 30.06.2016 tarihini takip eden 6 aylık dönem verilerini kullanarak portföye pay senedi seçimi yapmayı amaçlayan Tiryaki (2001) VZA (Veri Zarflama Analizi) yöntemini kullanmıştır. Çalışmanın sonucunda ise çalışmaya dahil edilen 21 firmanın 13'ü etkin olarak tespit edilmiş ve portföye dahil edilmesi gerektiği sonucu rapor edilmiştir.

Bouri vd. (2002), yapmış oldukları bir çalışmada Tunus Borsası'nda işlem gören 37 firmanın Ocak 1998-Haziran 2000 dönemine ilişkin aylık verilerini kullanarak AHP (Analytic Hierarchy Process) ve PROMETHEE yöntemleri kapsamında pay senetlerinden oluşan bir portföy oluşturmayı amaçlamışlardır. Çalışma sonucunda portföye dahil edilebilecek 7 firmanın tespit edildiği raporlanmıştır.

Küçükkocaoğlu (2002), çalışmasında Markowitz Ortalama Varyans modelini kullanarak İMKB-30 Endeksine kayıtlı firmaların pay senetlerinden oluşan bir portföy oluşturmayı amaçlamıştır. 4 Nisan 1999- Aralık 1999 dönemindeki günlük verilerin kullanılmış olduğu çalışmanın sonuçlarına göre söz konusu modele göre 6 firmanın pay senedi portföye dahil edilebilmiştir.

202004Q2-2007Q2 dönemini kapsayan örneklem için yapılmış olan çalışmada Chen (2008) Tayvan Borsası'nda faaliyet gösteren 8 büyük endüstri firmasının verilerini kullanarak portföy oluşturmayı amaçlamıştır. VZA yönteminin kullanıldığı çalışmanın sonucunda VZA yöntemine göre oluşturulan portföyün geleneksel yönteme göre oluşturulan portföylerden daha fazla getiri elde ettiği sonucuna ulaşılmıştır.

Marasovic ve Babic (2009) yılında yapmış oldukları bir çalışmada 2007-2008 dönemi verilerini kullanarak Zagreb Borsası'na kayıtlı olan ve farklı sektörlerde faaliyet gösteren 23 firmanın pay senedinden oluşan bir portföy oluşturmak için PROMETHEE yöntemini kullanmışlardır. Çalışma sonucunda portföye dahil edilebilecek 5 firma tespit edilmiştir.

2006-2011 dönemini kapsayan dönem için yapılan çalışmada Janani vd. (2012) TOPSIS yöntemini kullanarak Tahran Borsası'na kayıtlı 18 firmanın pay senetlerinden oluşturulacak bir portföy oluşturmayı hedeflemişlerdir. Çalışmanın sonucundan elde edilen bulgular TOPSIS (Technique For Order Preference By Similarity To An Ideal Solution) yönteminin portföy seçim sürecinde etkili bir teknik olduğunu göstermektedir. 
PROMETHEE yönteminin kullanıldığı bir çalışmada Şahin ve Akkaya (2013) İMKB50 endeksinde yer alan 34 firmanın 2011 y1lı çeyreklik verilerini kullanarak oluşturulacak olan bir portföye hisse senedi seçmeyi hedeflemişlerdir. Çalışma sonucunda 16 firmanın portföye dahil edilmesi gerektiği sonucuna ulaşılmıştır.

Lim vd., (2014) tarafindan yapılmış olan çalışmada 2001-2014 yıllarına ilişkin dönemde Güney Kore Borsası'nda faaliyet gösteren ve sayısı 490 ile 557 arasında değişen firmadan oluşan portföy seçimi VZA yöntemi ile yapılmıştır. Çalışmanın ampirik sonuçlarına göre yalnızca 30 firmanın portföye dahil edilmesi gerektiği tespit edilmiştir.

Sarıkaya ve Tatlıdil (2014), yapmış oldukları çalışmada Entropi ve ortalama varyans modeli kapsamında portföy seçimi yapmayı hedeflemişlerdir. BİST-30 Endeksi'nde yer alan firmaların 1Şubat 2013 ve 28 Şubat 2013 tarihleri arasındaki günlük verilerinin kullanıldığ çalışmanın sonuçlarına göre 12 firmanın etkin sınırlar içerisinde yer aldığı ve portföye dahil edilmesi gerektiği sonucu rapor edilmiştir.

2006-2010 zaman periyodunu kapsayan dönem için aylık verilerden yararlanarak BİST’te işlem görmekte olan ve farklı sektörlerde faaliyet gösteren 9 firmanın pay senetlerinden çeşitli portföyler elde ederek bu portföyleri karşılıklı olarak kıyaslamayı hedefleyen Özdemir (2016), portföy oluşturmak için Markowitz Ortalama Varyans Modeli ve Entropi yöntemini kullanmıştır. Çalışmanın sonucunda ise genel olarak Entropi yönteminde Markowitz modeline kıyasla daha fazla çeşitliliğin söz konusu olduğu görülmüştür.

Pala ve Aksaraylı (2017), yapmış oldukları bir çalışmada BİST-30 Endeksi'nde yer alan ve sürekli işlem gören 21 firmanın Ocak 2005 ve Aralık 2014 dönemine ilişkin aylık verilerini kullanılmışlardır. Ortalama varyans, TOPSIS ve PROMETHEE yöntemlerinin kullanıldığı çalışmada söz konusu firmaların pay senetlerinden oluşan portföy seçiminde hangi yöntemin daha etkili olduğunu tespit etmeyi amaçlayan çalışmadan elde edilen bulgulara göre, portföy oluşturmada PROMETHEE yönteminin diğer yöntemlere kıyasla daha etkili olduğu sonucuna ulaşılmıştır.

Söylemez ve Koç (2017), yapmış oldukları bir çalışmada 2017 yılını kapsayan dönem için BİST-100 Endeksinde en çok kazandıran 5 firma ile en çok kaybettiren 5 firmanın verilerini kullanarak AHP yöntemine dayalı bir portföy oluşturmayı amaçlamıştır. Çalışmanın sonucunda portföye dahil edilmesi gerek 3 firma tespit edilmiştir.

Gelecekte en iyi performansı gösterecek olan pay senetlerinin tespit edilmesinde Medyan ölçüsü ile ölçeklendirme, TOPSIS, AHP ve VZA ÇKKV yöntemlerinden hangisinin daha etkili olduğunu tespit etmeyi amaçlayan Pätäri vd. (2018), NYSE, AMEX ve NASDAQ'daki finansal olmayan firmaların 1971-2013 yılları verilerini kullanmışlardır. Çalışmada farklı ÇKKV tekniklerinin kullanılması sebebiyle gelecekteki en iyi performansı sergileyecek pay senetlerinin de farklılık gösterdiği tespit edilmiştir. Bu yüzden performans karşılaştırmaları için bir sağlamlık kontrolü olarak Carhart (1997) tarafından literatüre kazandırılan 4 faktörlü alfalar hesaplanmıştır. Sonuçlar, incelenen ÇKKV yöntemlerinin hisse senedi portföyü seçimine başarıyla uygulanabileceğini göstermektedir.

Kartal (2019), yapmış olduğu bir çalışmada BİST-30 Endeksinde yer alan firmaların verilerini kullanarak portföy seçimi yapmayı amaçlamıştır. Çalışma 2013-2016 dönemi 
verilerini kapsamakta olup MOORA (Multi-Objective Optimization By Ratio Analysis) yöntemine dayalı, geleneksel yönteme dayalı ve şans faktörüne dayalı üç adet portföy oluşturulmuştur. Çalışmanın sonucunda ise MOORA yöntemine dayalı olarak elde edilen portföyün diğer portföy seçeneklerine kıyasla daha fazla getiri elde ettiği tespit edilmiştir.

BİST-100 Endeksi'nde yer alan 39 firmanın Nisan 2017-Nisan 2018 dönemine ilişkin aylık verilerini kapsayan çalışmada Tekin vd., (2019), AHP ve Bulanık Kümeleme Analizi yöntemlerini kullanarak söz konusu firmaların pay senetlerinden portföyler oluşturmayı amaçlamışlardır. Çalışmadan elde edilen bulgulara göre reel sektör firmalarını kapsayan 2 numaralı kümede yer alan pay senetlerinden oluşan portföy diğerlerine göre daha iyi bir performans sergilemiştir.

\section{METODOLOJí}

$\mathrm{Bu}$ başlık altında çalışma kapsamına alınan firmaların değerlendirme ölçütlerine ilişkin ağırlık katsayılarının belirlenmesinde kullanılan SD yöntemi ile portföy seçiminde kullanılan PROMETHEE yöntemi teorik açıdan tanıtılacaktır.

\subsection{SD Yöntemi}

Bir problemin çözüm sürecinde değerlendirme kriterlerine ilişkin önem ağırlıkları belirlenirken uzman görüşlerinden faydalanmayan ve tamamıla objektif verilerden faydalanarak hesaplanma olanağı sunan SD yöntemi Eşit ağırlık, Entropi, CRITIC, SV ve CILOS ÇKKV yöntemleri gibi objektif bir ağırlıklandırma yöntemidir. Diakoulaki vd. (1995) tarafından literatüre kazandırılmış olan yöntem serilerin kendilerine ait ortalamadan ne kadar saptığının tespit edilmesinde kullanılan bir yöntemidir. Herhangi bir çalışma kapsamına alınan değerlendirme kriterlerinin zitlık yoğunluğunu baz alan ve j. kriterdeki verilere ait standart hatalar kapsamında ölçüm yapan yöntem 3 aşamalı bir uygulamadan oluşmaktadır (Aydın, 2020: 164; Diakoulaki vd., 1995: 765-766; Işık, 2020: 67; Işı1k ve Koşaroğlu, 2020: 1398-1399; Jahan vd., 2012: 413);

Aşama 1: Karar alternatifleri (bu çalışma kapsamında BİST Gıda, İçki ve Tütün Sektöründe faaliyet gösteren 26 firma) ve değerlendirme ölçütlerinden (söz konusu firmaların finansal performansın analiz edilmesi için seçilmiş olan değişkenler ya da ölçütler) oluşan $X$ karar matrisi Eşitlik (1)'de görüldüğü gibi oluşturulur.

$$
\mathrm{X}=\left[\left.\mathrm{x}_{\mathrm{ij}}\right|_{\mathrm{m} * \mathrm{n}}=\left[\begin{array}{cccc}
\mathrm{x}_{11} & \mathrm{x}_{12} & \cdots & \mathrm{x}_{1 \mathrm{n}} \\
\mathrm{x}_{21} & \mathrm{x}_{22} & \cdots & \mathrm{x}_{2 \mathrm{n}} \\
\vdots & \vdots & \ddots & \vdots \\
\mathrm{x}_{\mathrm{m} 1} & \mathrm{x}_{\mathrm{m} 2} & \cdots & \mathrm{x}_{\mathrm{mn}}
\end{array}\right]\right.
$$

Aşama 2: Karar matrisinin oluşturulmasından sonraki aşamada değerlendirme kriterlerinin fayda ve maliyet özellikleri göz önünde bulundurularak normalizasyon işlemi yapılmaktadır. Burada fayda yönlü kriterler Eşitlik (2), maliyet yönü kriterler ise Eşitlik (3) vasitasıyla normalize edilmektedir.

$$
x_{i j}^{*}=\frac{x_{i j}-x_{j}^{\min }}{x_{j}^{\max }-x_{j}^{\min }} ; i=1,2, \ldots \ldots m ; j=1,2, \ldots n
$$




$$
x_{i j}^{*}=\frac{x_{j}^{\max }-x_{i j}}{x_{j}^{\max }-x_{j}^{\min }} ; i=1,2, \ldots \ldots m ; j=1,2, \ldots n
$$

Aşama 3: Yöntemin son aşamasında ise ilk olarak Eşitlik (4) yardımıyla her bir değerlendirme kriterine ilişkin standart sapmalar ardından ise Eşitlik (5) yardımıyla da her bir değerlendirme kriterine ilişkin ağırlık katsayıları hesaplanmaktadır.

$$
\begin{aligned}
& \sigma_{j}=\sqrt{\frac{\sum_{i=1}^{m}\left(x_{i j}-\bar{x}_{j}\right)^{2}}{m}} ; j=1,2, \ldots n \\
& w_{j}=\frac{\sigma_{j}}{\sum_{j=1}^{n} \sigma_{j}} ; j=1,2, \ldots . m
\end{aligned}
$$

Burada en yüksek (en düşük) $w_{j}$ değerine sahip en önemli (en önemsiz) performans kriteri olarak değerlendirilmektedir.

\subsection{PROMETHEE Yöntemi}

Brans (1982) tarafından literatüre kazandırılmış olan ve Brans ve Vincke (1985) tarafından genişletilen PROMETHEE yöntemi temelde geliştirilmiş bir sıralama algoritmasıdır. Söz konusu ÇKKV yönteminde karar alternatiflerinin önem sırası PROMETHEE I (kısmi sıralama) ve PROMETHEE II (gerçek ya da tam sıralama) yöntemleri ile tespit edilmektedir. PROMETHEE yöntemi çalışmaya dahil edilen karar alternatiflerinin kendi aralarında ikili karşılaştırılmasına dayanmaktadır. $\mathrm{Bu}$ yöntemi diğer sıralama algoritmalarından farklı yapan özellik ise, değerlendirme kriterlerinin kendi arasındaki korelasyon düzeylerini temsil eden ağırlık katsayıları ile her bir değerlendirme kriterinin kendi iç korelasyonunu karar verme sürecinde bir arada dikkate alarak hesaplamalar yapılmasına olanak sağlamasıdır (Bedir ve Eren, 2015: 48). Söz konusu yöntem ise 7 aşamadan meydana gelmektedir (Brans ve Vincke, 1985: 650-652; Ishikaza ve Nemery, 2011: 960);

Aşama 1: Burada da yine diğer ÇKKV yöntemlerinde olduğu gibi ilk olarak değerlendirme kriterleri ve karar alternatiflerinden oluşan başlangıç karar matrisi (F) Eşitlik (6) doğrultusunda oluşturulmaktadır.

$$
F=\left[\begin{array}{ccrcl}
f_{1}\left(A_{1)}\right. & \cdots & f_{j}\left(A_{1)}\right. & \cdots & f_{n}\left(A_{1)}\right. \\
\vdots & \ddots & \vdots & \ddots & \vdots \\
f_{1}\left(A_{i}\right) & \cdots & f_{j}\left(A_{i}\right) & \cdots & f_{n}\left(A_{i}\right) \\
\vdots & \ddots & \vdots & \ddots & \vdots \\
f_{1}\left(A_{m}\right) & \cdots & f_{j}\left(A_{m}\right) & \cdots & f_{n}\left(A_{m}\right)
\end{array}\right]_{m \times n} ; i=1 \ldots m, j=1 \ldots n
$$

Aşama 2: Yöntemin ikinci aşamasında değerlendirme kriterlerine ilişkin tercih fonksiyonları tanımlanmaktadır. Bu fonksiyonlar ise Birinci Tip (Olağan), İkinci Tip(U-tipi), Üçüncü Tip(V-tipi), Dördüncü Tip (Seviyeli), Beşinci Tip (Lineer), Altıncı Tip (Gaussian) olmak üzere altı farklı şekilde tercih edilebilir.

Eğer karar verici tarafindan değerlendirme kriteri için herhangi bir tercih söz konusu değilse Birinci Tip (olağan) tercih fonksiyonu tercih edilmelidir. 
$>\quad$ Eğer karar verici değerlendirme kriteri için kendisinin belirlediği bir değerin üzerindeki değere sahip olan karar noktalarını tercih edecekse seçilmesi gereken tercih fonksiyonu İkinci Tip (U-tipi) tercih fonksiyonudur.

Eğer karar verici değerlendirme kriterleri için ortalamanın üzerindeki değerlere sahip olan karar noktaları tercih edilirse fakat ortalamanın altındaki değerler de ihmal edilmek isteniyor ise bu durumda seçilmesi gereken tercih fonksiyonu Üçüncü Tip (V tipi) tercih fonksiyonudur.

$>\quad$ Eğer karar verici bu tercihini belirli bir değer aralığında yer alan karar noktaları için kullanacak ise bu durumda yapılması gereken Dördüncü Tip (seviyeli) fonksiyonunu tercih etmektir.

Eğer karar verici bu noktada tercihini ortalamanın üzerindeki değerlere sahip karar noktalarından yana kullanmayı isterse tercih edecek olduğu fonksiyon Beşinci Tip (Lineer) tercih fonksiyonudur.

Eğer karar verici tercihinde değerlendirme kriterlerinin ortalamadan sapma değerlerini belirleyici faktör olarak kullanmak isterse bu durumda yapılması gereken tercih Altıncı Tip (Gaussian) tercih fonksiyonudur.

Aşama 3: Bir önceki aşamada belirlenen tercih fonksiyonları göz önünde bulundurularak bu aşamada her bir değerlendirme kriteri için karar alternatiflerinin ikili kıyaslaması yapılarak ortak tercih fonksiyonları tespit edilir. Bu amaçla A ve B'nin iki karar alternatifini temsil ettiği varsayıldığında ortak tercih fonksiyonu ( $\mathrm{P}(\mathrm{a}, \mathrm{b})$ ) Eşitlik (7) yardımıyla hesaplanabilmektedir.

$$
P(a, b)=\left\{\begin{array}{cc}
0 & , f(a) \leq f(b) \\
p[f(a)-f(b)] & , f(a)>f(b)
\end{array}\right.
$$

Burada belirtmemiz gereken nokta, karar alternatiflerinin ikili kıyaslaması yapılırken kriterin fayda ve maliyet özelliği dikkate alınması gerektiğidir.

Aşama 4: Ortak tercih fonksiyonlarının tespitinden sonra bu değerlerden faydalanılarak karar alternatiflerine ilişkin tercih indeksleri Eşitlik (8)'den faydalanılmak suretiyle hesaplanmaktadır.

$$
\pi(a, b)=\frac{\sum_{1=1}^{\mathrm{k}} \mathrm{w}_{\mathrm{i}} \times \mathrm{P}_{\mathrm{i}}(\mathrm{a}, \mathrm{b})}{\sum_{\mathrm{l}=1}^{\mathrm{k}} \mathrm{w}_{\mathrm{i}}}
$$
etmektedir.

Yukarıdaki Eşitlikte yer alan k katsayısı değerlendirme faktörü sayısını temsil

Aşama 5: Bu aşamada karar alternatiflerine ait pozitif $\left(\varphi^{+}\right)$üstünlük ve negatif $\left(\varphi^{-}\right)$ üstünlük değerleri sırasıyla Eşitlik (9) ve Eşitlik (10) yardımıyla elde edilmektedir.

$$
\begin{aligned}
& \varphi^{+}(\mathrm{a})=\frac{1}{\mathrm{n}-1} \sum \pi(\mathrm{a}, \mathrm{b}) \\
& \varphi^{-}(\mathrm{a})=\frac{1}{\mathrm{n}-1} \sum \pi(\mathrm{b}, \mathrm{a})
\end{aligned}
$$

Aşama 6: Yöntemin altıncı aşamasında ise PROMETHEE I ile kısmi öncelikler tespit edilmektedir. Bir önceki aşamada elde edilen pozitif ve negatif üstünlük değerleri ikili olarak 
kıyaslanarak karar alternatiflerinin birbirlerine göre üstün olduğu durumlar, birbirinden farksız olan alternatifler ve birbirleri ile kıyaslanamayacak alternatifler tespit edilir. Burada a ve $b$ iki alternatifi temsil ettiği düşünüldüğünde kısmi önceliklerin belirlenmesi aşamasında karşılaşılacak olan 3 durum Eşitlik (11)'de yer almaktadır.

Aşağıdaki koşullar içerisinden herhangi biri sağlanıyorsa a alternatifi b alternatifine göre tercih edilebilir şeklinde yorumlanmaktadır.

$$
\begin{aligned}
& \varphi^{+}(\mathrm{a})>\varphi^{+}(\mathrm{b}) \text { ve } \varphi^{-}(\mathrm{a})<\varphi^{-}(\mathrm{b}) \\
& \varphi^{+}(\mathrm{a})>\varphi^{+}(\mathrm{b}) \text { ve } \varphi^{-}(\mathrm{a})=\varphi^{-}(\mathrm{b}) \\
& \varphi^{+}(\mathrm{a})=\varphi^{+}(\mathrm{b}) \text { ve } \varphi^{-}(\mathrm{a})<\varphi^{-}(\mathrm{b})
\end{aligned}
$$

Aşağıdaki Eşitlik (12)'de ifade edildiği şekilde bir koşul söz konusu ise a alternatifi b alternatifinden farksızdır;

$$
\begin{aligned}
& \varphi^{+}(\mathrm{a})=\varphi^{+}(\mathrm{b}) \text { ve } \\
& \varphi^{-}(\mathrm{a})=\varphi^{-}(\mathrm{b})
\end{aligned}
$$

Ancak bunlardan farklı olarak Eşitlik (13)'de yer alan koşullardan biri söz konusu ise a alternatifi $b$ alternatifi ile kıyaslanamaz;

$$
\begin{aligned}
& \varphi^{+}(\mathrm{a})>\varphi^{+}(\mathrm{b}) \text { ve } \varphi^{-}(\mathrm{a})>\varphi^{-}(\mathrm{b}) \\
& \varphi^{+}(\mathrm{a})<\varphi^{+}(\mathrm{b}) \text { ve } \varphi^{-}(\mathrm{a})<\varphi^{-}(\mathrm{b})
\end{aligned}
$$

Aşama 7: Yöntemin son aşamasında PROMETHEE II ile karar alternatiflerine ilişkin tam sıralamalar tespit edilir. Karar alternatiflerine ilişkin tam sıralama skorlarının belirlenebilmesi için her bir karar alternatifine Eşitlik (14) uygulanmalıdır. En son ise elde edilen skorlar büyükten küçüğe doğru sıralanarak hesaplamalar tamamlanmış olmaktadır.

$$
\varphi(\mathrm{a})=\varphi^{+}(\mathrm{a})-\varphi^{-} \text {(a) }
$$

a ve b ile ifade edilen iki adet karar alternatifi için hesaplanan tam öncelik değeri dikkate alınarak Eşitlik (15)'te gösterildiği gibi kararlar alınır.

$$
\begin{aligned}
& \varphi(\mathrm{a})>\varphi(\mathrm{b}) \text { ise, a alternatifi daha üstündür, } \\
& \varphi(\mathrm{a})=\varphi(\mathrm{b}) \text { ise, a ve } \mathrm{b} \text { alternatifleri farksızdır }
\end{aligned}
$$

\section{4. ÖNERILEN MODELIN UYGULANMASI}

Bu bölümde SD ve PROMETHEE yöntemlerinden oluşan bütünleşik modele dayalı olarak karar verme yaklaşımlarının BİST’te işlem gören $26^{1}$ Gıda, İçecek ve Tütün sektörü

\footnotetext{
${ }^{1}$ Anadolu Efes Biracılık ve Malt Sanayii A.Ş. (AEFES), A.V.O.D. Kurutulmuş Gıda ve Tarım Ürünleri A.Ş. (AVOD), Banvit Bandırma Vitaminli Yem Sanayii A.Ş.(BANVT), Coca-Cola İçecek A.Ş.(CCOLA), Dardanel Önentaş Gıda Sanayi A.Ş. (DARDL), Ekiz Kimya Sanayi ve Ticaret A.Ş.(EKIZ), Ersu Meyve ve Gıda Sanayi
} 
firma performanslarının değerlendirilmesi amaçlanmıştır. Çalışmada örneklem olarak Gıda, İçecek ve Tütün sektörünün kullanılmasındaki sebep bu sektörün çalışma için yeterli firma ölçeğine sahip olması ve daha önceki çalışmalarda bu sektörün kullanılmamasıdır. Bu amaçla ilk olarak SD yönteminden faydalanılarak seçilen değerlendirme kriterlerinin önem ağırlıkları tespit edilecektir. İkinci aşamada ise SD yöntemine dayalı olarak elde edilen kriter ağırlıkları PROMETHEE yöntemine dahil edilerek söz konusu sektör firmalarının performans skorları tespit edilecektir. Son aşamada ise PROMETHEE yöntemine göre etkin sınırın üzerinde olan firmaların pay senetlerinden bir portföy oluşturularak söz konusu portföyün performansı değerlendirilecektir.

\section{1. Çalışmada Kullanılan Veriler}

Analiz kapsamında incelenen sektör firmalarının 2015-2020 dönemine ait y1llık verilerinden yararlanılmıştır. Çalışma döneminin seçilmesinde verilerin güncel olması, yöntemin uygulanması ve raporlanmasıyla ilgili etkenler belirleyici olmuştur. Değerlendirme kriterlerinin seçilmesinde firma performansıyla ilgili literatür dikkate alınmıştır. Kamuyu Aydınlatma Platformu'ndan (KAP) elde edilen veriler yardımıyla hesaplanan finansal performans göstergelerine ilişkin bilgiler Tablo 1'de sunulmuştur.

Tablo 1. Değerlendirme Kriterleri

\begin{tabular}{clcl}
\hline Sıra & Seçilen Değerlendirme Kriterleri & Nitelik & Kod \\
\hline $\mathbf{1}$ & Piyasa Değeri/Defter Değeri Oranı & Minimum & PD/DD \\
$\mathbf{2}$ & Kur Riski (Pasif) Oranı & Minimum & KRP \\
$\mathbf{3}$ & Kur Riski (Aktif) Oranı & Minimum & KRA \\
$\mathbf{4}$ & Fiyat / Kazanç Oranı & Minimum & F/KO \\
$\mathbf{5}$ & Aktif Karlılık Oranı (\%) & Maximum & AK \\
$\mathbf{6}$ & Özsermaye Karlılık Oranı (\%) & Maximum & ÖKK \\
$\mathbf{7}$ & Net Kar Marjı (\%) & Maximum & NKM \\
$\mathbf{8}$ & Aktif Büyüme Oranı (\%) & Maximum & ABO \\
$\mathbf{9}$ & Net Satış Büyümesi (\%) & Maximum & NSB \\
$\mathbf{1 0}$ & Özsermaye Büyümesi (\%) & Maximum & ÖSB \\
$\mathbf{1 1}$ & Cari Oran* & Maximum & CO \\
$\mathbf{1 2}$ & Aktif Devir Hızı & Maximum & ADH \\
$\mathbf{1 3}$ & Yurt Dışı Satışlar / Toplam Satışlar (\%) & Maximum & YS/TS \\
$\mathbf{1 4}$ & Kaldıç Oranı (\%) & Minimum & KO \\
$\mathbf{1 5}$ & Oynaklık & Minimum & OY \\
\hline
\end{tabular}

Not: *Cari oran belirli sınırlar arasında $(1,5-2,5)$ normal kabul edilmekte ve bu sınırlar içerisinde maksimum olması arzu edilmektedir. Bunun dışındaki oranlar fayda ya da maliyet özeliğine göre değerlendirilmiştir.

A.Ş. (ERSU), Frigo-Pak Gıda Maddeleri Sanayi ve Ticaret A.Ş. (FRIGO), Kent Gıda Maddeleri Sanayii ve Ticaret A.Ş. (KENT), Kerevitaş Gıda Sanayi ve Ticaret A.Ş. (KERVT), Konfrut Gıda Sanayi ve Ticaret A.Ş. (KNFRT), Kristal Kola ve Meşrubat Sanayi Ticaret A.Ş. (KRSTL), Merko Gıda Sanayi ve Ticaret A.Ş. (MERKO), Oylum Sınai Yatırımlar A.Ş. (OYLUM), Penguen Gıda Sanayi A.Ş. (PENGD), Pınar Entegre Et ve Un Sanayii A.Ş. (PETUN), Pınar Su ve İçecek Sanayi ve Ticaret A.Ş. (PINSU), Pınar Süt Mamulleri Sanayii A.Ş. (PNSUT), Selçuk Gıda Endüstri İhracat İthalat A.Ş. (SELGD), Tat Gıda Sanayi A.Ş. (TATGD), Taze Kuru Gıda Sanayi ve Ticaret A.Ş. (TKURU), Tukaş Gıda Sanayi ve Ticaret A.Ş. (TUKAS), Türk Tuborg Bira ve Malt Sanayii A.Ş. (TBORG), Ulusoy Un Sanayi ve Ticaret A.Ş. (ULUUN), Ülker Bisküvi Sanayi A.Ş. (ULKER), Vanet Gıda Sanayi İç ve Dış Ticaret A.Ş. (VANGD). 


\subsection{SD Yöntemine İlişkin Bulgular}

Analiz kısmında ilk olarak SD yöntemi kapsamında, seçilen değerlendirme kriterlerine ilişkin ağırlık skorları hesaplanacaktır. Ancak çalışmanın birden çok zaman dönemini kapsaması nedeniyle bu bölümde örnek teşkil etmesi açısından yalnızca 2020 yılına ilişkin bulgular tablolar yardımıyla sunulacaktır. En son kısımda yer alan Tablo 5'da ise tüm yıllara ilişkin bulgular toplu olarak sunulacaktır. SD yönteminin ilk aşamasında 26 adet karar alternatifi ve 16 adet değerlendirme kriterlerinden oluşan başlangıç karar matrisi Eşitlik (1) kapsamında düzenlenerek Tablo 2'te rapor edilmiştir.

Tablo 2. Karar Matrisi (2020 Y11 İçin)

\begin{tabular}{|c|c|c|c|c|c|c|c|c|c|c|c|c|c|c|c|}
\hline & Min. & Iin. & Min. & Min. & Max. & Max. & Max. & Max. & Max. & Max. & Max. & Max. & Max. & Min. & Min. \\
\hline & PD/DD & KRP & KRA & F/KO & AK & $\mathbf{I K}$ & NKM & ABO & NSB & ÖSB & CO & ADH & YS/TS & KO & OY \\
\hline . & & 170 & 2380 & .800 & 690 & 270 & 00 & 600 & 00 & 2.820 & 00 & 5400 & 37.3600 & 00 & 329 \\
\hline & & & & & & & & & & 07 & & & & & \\
\hline ANVT & & & & -25 & & & & & & 270 & & & & & \\
\hline & 2.3 & & 91 & & & & & & 00 & 61 & & & & 00 & \\
\hline ARDL & 13.5 & & & & & & & 300 & & 4.0 & & & 200 & 500 & \\
\hline EKIZ & 4.5500 & 013 & & 252.0 & 1100 & 9500 & 00 & 7.2800 & -23.8700 & .09 & 00 & 100 & 000 & 500 & 4.61 \\
\hline $\mathbf{U}$ & & 038 & 28 & & 700 & 500 & & & & 50 & & 00 & & 100 & 100 \\
\hline RIGO & 0 & & & & & & & 75 & 00 & 37 & & 00 & 00 & 00 & \\
\hline ENT & 94 & 12 & 5 & & & & & & & 23 & 0 & 0 & 00 & 00 & \\
\hline KERVT & & 20 & & & & & & & & 51 & & & 00 & 00 & \\
\hline ENFRT & 4.2 & & & & & & & & & 93 & & 00 & 00 & 00 & \\
\hline$\Gamma \mathbf{L}$ & 1.9 & & & & & 00 & & & & 27 & & 000 & & 00 & \\
\hline IERKO & 8.5 & & & -4 & 600 & -17.08 & & & 300 & 153.43 & & 00 & & 00 & \\
\hline YLUM & 2.0 & 22 & 90 & 4 & 0 & 5. & & 4 & & 27 & 0 & 00 & 0 & 00 & .2880 \\
\hline $\mathbf{D}$ & 2. & & & & & 0 & & & & & & 0 & & & \\
\hline PETUN & 1.3 & & 30 & 58 & 0 & & & & & 34 & 00 & 00 & 00 & 00 & 00 \\
\hline PINSU & 4.2 & & 0.0035 & -8.370 & 62 & .82 & & & & 19 & & 00 & 00 & 00 & 00 \\
\hline PNSUT & 0.9300 & .0298 & 0.0165 & 24.56 & 2.3200 & 4.1000 & & 23. & & .19 & & 1.1700 & 11.7100 & 00 & 0.7093 \\
\hline SELGD & 2.5 & & & & 2.1600 & 00 & & 34. & & 17 & & po & 00 & 00 & 36 \\
\hline ГAT & & & & & & & & & & & & & & & 353 \\
\hline TKURU & & & & -47.42 & -77.520 & -950.0 & & -28 & & .00 & & 00 & & 000 & \\
\hline TUKAS & 4.0400 & 567 & 0.0249 & 17.33 & 12.45 & 30.860 & & 54. & 00 & 95.62 & 00 & 000 & 31.6800 & 00 & .0464 \\
\hline TBORG & 3.3500 & 0.2990 & 0.0158 & 11.66 & 17.52 & 33.50 & 20.29 & 36.4700 & 19.2600 & 40.17 & 0.0000 & 0.8600 & 5.2090 & 47.0900 & 0.2261 \\
\hline ULUUN & 3.6400 & 0.0399 & 0.0091 & 37 & 30 & 13.160 & & 30 & & 69 & 00 & 2.9400 & 72.1000 & 200 & \\
\hline JLF & & & & & 200 & & & & & & & & 300 & 200 & 2.4900 \\
\hline IANGD & 5.3200 & 0.0000 & 0.0000 & 29.55 & 17.04 & 19.79 & 75.03 & 21.5500 & 37.9000 & 21.93 & 0.0000 & 0.2300 & 1.0000 & 13.8000 & 18.93 \\
\hline
\end{tabular}

Tablo 3'te analiz kapsamında incelenen firmalara ilişkin değerlendirme kriterlerinin fayda ve maliyet özellikleri dikkate alınarak hesaplanmış olan normalize edilmiş karar matrisi yer almaktadır. Normalize edilmiş karar matrisi hesaplanırken değerlendirme kriterleri eğer fayda yönlü ise Eşitlik (2) kullanılarak, eğer ki değerlendirme kriterleri maliyet yönlü ise bu durumda da Eşitlik (3) kullanılarak hesaplamalar yapılmıştır. 
Tablo 3. Normalize Karar Matrisi (2020 Y1lı İçin)

\begin{tabular}{|c|c|c|c|c|c|c|c|c|c|c|c|c|c|c|c|}
\hline & D/DD & KRP & KRA & F/KO & AK & ÖKK & NKM & ABO & NSB & ÖSB & $\mathrm{CO}$ & ADH & YS/TS & KO & OY \\
\hline AEFES & 0.9991 & 0.9269 & 0.9165 & 0.8550 & 0.7978 & 0.9636 & 0.6089 & 0.1209 & 0.4986 & 0.0415 & 0.0000 & 0.1144 & 0.3930 & 0.5838 & 0.9950 \\
\hline AVOD & 0.9046 & 76 & 0.9608 & 1.0000 & 7671 & 5513 & 816 & 1321 & 649 & 1040 & 0.0000 & 0.1697 & 9302 & 0.3611 & 14 \\
\hline BANVT & 0.9450 & 0.9450 & 0.9884 & 0.8825 & 55 & 0. & 628 & 1836 & 305 & 0.0283 & 1.0000 & 0.4908 & 1439 & 518 & 43 \\
\hline CCOLA & 9847 & 0 & 0.9547 & 0.8557 & 15 & 48 & 389 & 0.1514 & 87 & 0.0908 & 0 & 0.2177 & 6054 & 411 & 9992 \\
\hline ARDL & 0.8603 & 0 & 0.0000 & 0.8534 & 1.0000 & 0.9581 & 452 & 1.0000 & 1.0000 & 1.0000 & 0. & 17 & 1116 & 2308 & 9226 \\
\hline EKIZ & 0.9613 & & 78 & 0.6962 & 0.7850 & 0.9593 & 947 & 0.1119 & 0.1962 & 0.0896 & 0.0 & 09 & 0000 & 0.2754 & 0.8457 \\
\hline RSU & 657 & & 90 & 0.6573 & 0.7906 & 0. & 01 & 0.0801 & 0.9057 & .0535 & $1 .($ & 58 & 0000 & 0.8532 & 0.9969 \\
\hline RIGO & 0.9252 & 0. & 36 & 0.8493 & 0.9 & 0.9 & 830 & 0.3230 & 0.8076 & 0.2255 & 0.0 & 399 & 1.0000 & 0.4249 & 0.9935 \\
\hline KENT & 0.0000 & 0 & 0.9 & 0.5423 & 0.9295 & 0.98 & 0.6618 & 0.2351 & 0.5 & 0.2300 & 0.0 & 395 & 0.2943 & 0.7372 & 0.6590 \\
\hline ERVT & 75 & 0. & & 0.8593 & 0. & 1.0000 & 62 & 38 & 94 & 0.1921 & 1.0 & 68 & 0.1109 & 903 & 0.9983 \\
\hline NFRT & 550 & & & 0.8470 & 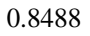 & 0. & & 56 & 44 & 0.0 & 0.6 & 19 & 0.6894 & 01 & 979 \\
\hline RSTL & 0.9887 & 0. & 0. & 0.8293 & 0.8 & 0.9 & 58 & 09 & 93 & 0.0828 & 0.0 & 10 & 0.0962 & 352 & 0.9961 \\
\hline IERKO & 0.9188 & 0.5 & 0. & 0.8683 & 0. & 0.9 & 18 & 0.2931 & 0.0 & 0.4189 & 0.0 & 07 & 0.1145 & 0.4571 & 0.9274 \\
\hline YLUM & 878 & 0.8 & 0. & 0.8338 & 0.8 & 0.9 & 74 & 14 & 0.6 & 0.1963 & 0.0 & 341 & 0.0000 & 0.6269 & 0.9996 \\
\hline ENGD & 0.9840 & 0.9 & 0. & 0.0000 & 0.78 & 0.9 & 34 & 23 & 0.8 & 0.2172 & 1.0 & 24 & 0.7075 & 0.7765 & 0.9665 \\
\hline rUN & 0.9960 & 0.95 & $0 . c$ & 0.8584 & 0.8790 & 0.9 & 39 & 0.1834 & 0.4727 & 0.0950 & 1.0000 & 325 & 0.0278 & 0.8186 & 0.9956 \\
\hline INSU & 0.9641 & 0.5 & & 0.8712 & 0.6 & 0.8980 & 38 & 349 & 0.3615 & 0.1985 & 0.0000 & 328 & 0.1351 & 0.2527 & 0.9922 \\
\hline PNSUT & 1.0000 & 0.98 & 0.9 & 0.8491 & 0.8042 & 0.96 & 0.6031 & 0.1636 & 0.5439 & 0.0922 & 0.0000 & 0.3469 & 0.1158 & 0.6488 & 0.9989 \\
\hline SELGD & 0.9825 & 0.886 & 0.9447 & 0.7860 & 0.8026 & 0.9600 & 0.6115 & 0.1963 & 0.7276 & 0.1792 & 0.0000 & 0.1402 & 0.6899 & 1.0000 & 0.9791 \\
\hline TATGD & 0.9901 & 0.9672 & 0.9900 & 0.8603 & 0.9252 & 0.9839 & 0.7055 & 0.1748 & 0.7210 & 0.1104 & 0.0000 & 0.1697 & 0.2764 & 0.6325 & 0.9988 \\
\hline TKURU & 0.9942 & 0.3443 & 0.9888 & 0.8975 & 0.0000 & 0.0000 & 0.0000 & 0.0000 & 0.5985 & 0.0000 & 0.0000 & 0.1771 & 0.2140 & 0.0000 & 0.0000 \\
\hline TUKAS & 0.9667 & 0.9646 & 0.9913 & 0.8539 & 0.9062 & 0.9884 & 0.6769 & 0.2595 & 0.5915 & 0.2793 & 0.0000 & 0.2103 & 0.3316 & 0.5223 & 1.0000 \\
\hline TBORG & 0.9741 & 0.8133 & 0.9945 & 0.8578 & 0.9573 & 0.9911 & 0.7025 & 0.2027 & 0.5242 & 0.1453 & 0.0000 & 0.2325 & 0.0455 & 0.6221 & 0.9997 \\
\hline ULUUN & 0.9710 & 0.975 & 0.9968 & 0.8438 & 0.8103 & 0.9706 & 0.5977 & 0.1847 & 0.6998 & 0.1466 & 0.0000 & 1.0000 & 0.7686 & 0.2891 & 0.9936 \\
\hline ULKER & 0.9958 & 0.9 & 0.9937 & 0.8606 & 0.8475 & 0.9776 & 0.6510 & 0.2133 & 0.5335 & 0.1185 & 0.0000 & 0.1402 & 0.1603 & 0.4359 & 0.9960 \\
\hline VANGD & 0.9530 & 1.0000 & 1.0000 & 0.8457 & 0.9525 & 0.9772 & 1.0000 & 0.1563 & 0.6659 & 0.1013 & 0.0000 & 0.0000 & 0.0000 & 0.9924 & 0.9692 \\
\hline
\end{tabular}

Yöntemin son aşamasında ise her bir değerlendirme kriterine ilişkin standart sapma ve ağırlık skorları sırasıyla Eşitlik (4) ve Eşitlik (5)'ten faydalanılarak hesaplanmış olup elde edilen sonuçlar Tablo 4'te sunulmuştur.

Tablo 4. Kriterlere İlişkin Hesaplanan $\sigma_{\mathrm{j}}$ ve $w_{\mathrm{j}}$ Değerleri (2020 Y1lı İçin)

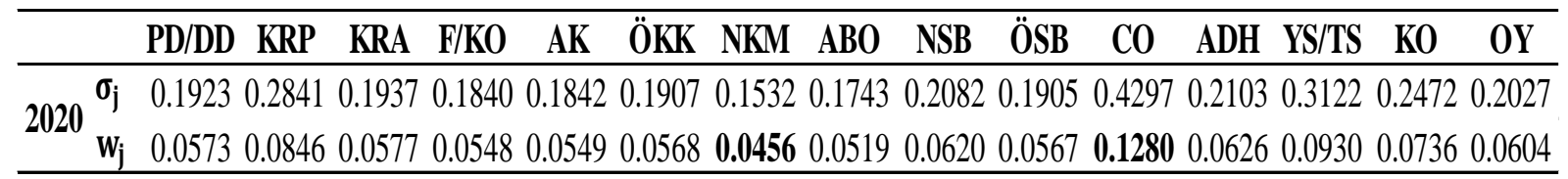

Tablo 4'te yer alan $\mathbf{w}_{\mathbf{j}}$ değerlerine dikkate alındığında 2020 yılını kapsayan dönem için analiz kapsamında incelenen Gıda, İçecek ve Tütün Sektörü firmalarının performansı üzerinde etkili olan en önemli performans kriterinin (CO) ile kodlanan Cari Oran $(0,1280)$ olduğu tespit edilmiştir. Buna ilaveten söz konusu dönemde firma performansı üzerinde etkisi en az olan kriterin ise (NKM) ile kodlanan Net Kar Marjı Oranı $(0,0456)$ olduğu tespit edilmiştir.

Tablo 5'te ise analiz kapsamında incelenen tüm yıllar (2015-2020) için hesaplanan standart sapma ve kriter ağırlıklarına ilişkin sonuçlar yer almaktadır. 
Tablo 5. Kriterlere İlişkin Hesaplanan $\sigma_{j}$ ve $w_{j}$ Değerleri (Tüm Ylllar İçin)

\begin{tabular}{|c|c|c|c|c|c|c|c|c|c|c|c|c|c|c|c|}
\hline & /DD & KRP & RA & KO & AK & ÖKK & JKM & ABO & NSB & ÖSB & $\mathrm{CO}$ & ADH & YS/TS & KO & OY \\
\hline \multirow{2}{*}{$2015 \begin{array}{l}\sigma_{j} \\
w_{j}\end{array}$} & 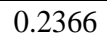 & 0.2 & 0 & 47 & 989 & 0.2 & c & 0.2068 & 153 & 0.1866 & 0.4707 & 0.1977 & 0.2812 & 0.1862 & 0.2431 \\
\hline & 0681 & 0.0 & 0.0559 & 0.0560 & 0.0572 & 0.0632 & 7 & 0. & & 0.0537 & 0.1354 & 0.0569 & 0.0809 & 0.0 & 0 \\
\hline \multirow{2}{*}{$2016 \begin{array}{l}\sigma_{j} \\
w_{j}\end{array}$} & & & & & & & & & 0 & 6 & & 0 & & & 0.2 \\
\hline & 0.0483 & 0.05 & 0 & 0.0 & 0. & 0.0508 & 0 & 0.0897 & 0 & 0.0490 & 11 & 92 & & & 0.0 \\
\hline \multirow{2}{*}{$2017 \begin{array}{c}\sigma_{j} \\
w_{j}\end{array}$} & & & & & & & & & & & & & & & \\
\hline & 0.06 & 0.0691 & 0 & 0.0 & 0.0 & 0.0571 & 0 & 0.0 & $\mathbf{0 . 0}$ & 0.0571 & 09 & 0. & & & 0.0 \\
\hline \multirow{2}{*}{$2018 \begin{array}{l}\sigma_{j} \\
w_{j}\end{array}$} & & & & & & & & & & 0.20 & & & & & \\
\hline & 0.0659 & 0.0630 & 0.0 & 0.0532 & 0.0548 & 0.0655 & 0.0 & 0.0694 & & 0.0565 & 0.1 & 505 & & & 0.0751 \\
\hline \multirow{2}{*}{$2019 \begin{array}{c}\sigma_{j} \\
w_{j}\end{array}$} & 0.1 & 0.2 & & 0.2247 & 0.2249 & 0.2376 & & 0.1 & 0.2 & 0.1833 & 0.4 & 0. & & & 0.1 \\
\hline & 0.0573 & 0.0635 & 881 & 0.0657 & 0.0658 & 0.0695 & 0.0542 & 0.0555 & 0.0652 & 0.0536 & 0.1257 & 0.0636 & 0.0908 & 0.0533 & 0.0582 \\
\hline \multirow{2}{*}{$2020 \begin{array}{l}\sigma_{j} \\
w_{j}\end{array}$} & 0.1923 & 0.28 & & 0.1840 & 0.0 & 0.1907 & & & 0.2 & 0.1905 & & & & & 0.2027 \\
\hline & 0.0573 & 0.0846 & 0.0577 & 0.0548 & 0.0549 & 0.0568 & 0.0456 & 0.0519 & 0.0620 & 0.0567 & 0.1280 & 0.0626 & 0.0930 & 0.0736 & 0.0604 \\
\hline
\end{tabular}

Tablo 6'da yer alan $w_{j}$ değerlerine göz önüne alındığında çalışma kapsamına alınan sektör firmalarının performansı üzerinde en etkin olan değerlendirme kriterinin tüm yıllarda cari oran kriteri olduğu buna karşın firmaların performansı üzerinde etkisi an az olan kriterin ise yıllara göre değişkenlik gösterdiği sonucuna ulaşılmıştır. Daha açık bir ifade ile 2015 yılını kapsayan zaman periyodunda firma performansı üzerinde etkisi en az olan değerlendirme kriteri Kaldıraç Oranı (KO) olurken, 2016 yılını kapsayan dönem için ise bu kriterin Piyasa Değeri/ Defter Değeri (PD/DD) oranı olduğu görülmektedir.

\subsection{PROMETHEE Yöntemine İlişkin Bulgular}

Analizin ilk aşamasında SD yönteminden elde edilen sonuçlar, ikinci aşamada Visual PROMETHEE Academic Edition 1.4.0.0 paket programı kapsamında PROMETHEE I ve PROMETHEE II yöntemlerine dayalı olarak incelenmiş̧tir. Ancak burada da SD yönteminde belirtildiği üzere çalışmanın birden fazla dönemi kapsaması nedeniyle yine firmaların yalnızca 2020 yılına ilişkin bulguları rapor edilmiştir. Çalışmanın sonunda ise yine SD yönteminde olduğu toplu sonuçlar tablolar yardımıyla sunulmuştur.

Yöntemin ilk aşamasında, diğer tüm ÇKKV yöntemlerinde olduğu gibi başlangıç karar matrisi oluşturulmaktadır. Eşitlik (6) kapsamında oluşturulan karar matrisi Tablo 2'de yer almaktadır. Daha sonra yöntemin ikinci aşamasında analiz kapsamında incelenen değerlendirme kriterlerine en uygun olan tercih fonksiyonları belirlenmiştir. Tercih fonksiyonları belirlenirken hem finansal oranların yapısına hem de serilerdeki standart sapmalara bağlı olarak daha çok nicel kriterlerin analizinde kullanılan Üçüncü Tip (V tipi) ve Beşinci Tip (Lineer) fonksiyonlar tercih edilmiştir.

Yöntemin üçüncü aşamasında hesaplanan tercih fonksiyonları baz alınarak dördüncü aşamada her karar alternatifi çifti için tercih indeksleri tespit edilmiştir. Söz konusu indekslerden faydalanılarak yöntemin beşinci aşamasında firmaların +1 ve -1 değer aralığındaki pozitif ve negatif değerleri tespit edilmektedir. Burada ifade edilen pozitif değerler, analiz kapsamına alınan karar alternatiflerinin diğer alternatiflere kıyasla pozitif üstünlük değerini ifade ederken negatif değerler ise karar alternatiflerinin diğer alternatiflere kıyasla ne derece zayıf olduklarını ifade etmektedir. 
Tablo 6'da analiz kapsamına alınan sektör firmalarının 2020 yılı için hesaplanmış olan pozitif ve negatif üstünlük değerleri yer almaktadır. Bu sonuçlar dikkate alındığında pozitif üstünlük değeri büyük olan firma performanslarının daha yüksek olduğu, buna karşın pozitif üstünlük değeri küçük olan firma performanslarının daha düşük olduğu söylenebilir.

Tablo 6. Gıda, İçecek ve Tütün Sektörü Firmalarının Pozitif ve Negatif Üstünlük Değerleri (2020 Y11ı İçin)

\begin{tabular}{ccccc}
\hline Sira & Firma & $\mathbf{P h}_{\mathbf{i}}$ & $\mathbf{P h}_{\mathbf{i}}^{+}$ & $\mathbf{P h}_{\mathbf{i}}^{-}$ \\
\hline $\mathbf{1}$ & TBORG & 0.3979 & 0.5752 & 0.1772 \\
$\mathbf{2}$ & TATGD & 0.3902 & 0.5554 & 0.1651 \\
$\mathbf{3}$ & FRIGO & 0.3721 & 0.5658 & 0.1937 \\
$\mathbf{4}$ & TUKAS & 0.3352 & 0.5485 & 0.2134 \\
$\mathbf{5}$ & KERVT & 0.3178 & 0.5283 & 0.2104 \\
$\mathbf{6}$ & VANGD & 0.2981 & 0.5369 & 0.2388 \\
$\mathbf{7}$ & DARDL & 0.2789 & 0.5774 & 0.2985 \\
$\mathbf{8}$ & KENT & 0.2596 & 0.5104 & 0.2508 \\
$\mathbf{9}$ & PETUN & 0.1909 & 0.4906 & 0.2998 \\
$\mathbf{1 0}$ & CCOLA & 0.1617 & 0.4599 & 0.2983 \\
$\mathbf{1 1}$ & KNFRT & 0.1421 & 0.4381 & 0.2961 \\
$\mathbf{1 2}$ & ULKER & 0.1349 & 0.4364 & 0.3015 \\
$\mathbf{1 3}$ & SELGD & -0.0004 & 0.3410 & 0.3414 \\
$\mathbf{1 4}$ & ULUUN & -0.0033 & 0.3636 & 0.3670 \\
$\mathbf{1 5}$ & OYLUM & -0.0294 & 0.3253 & 0.3547 \\
$\mathbf{1 6}$ & PNSUT & -0.0632 & 0.3039 & 0.3670 \\
$\mathbf{1 7}$ & KRSTL & -0.0900 & 0.3032 & 0.3932 \\
$\mathbf{1 8}$ & PENGD & -0.1236 & 0.3177 & 0.4413 \\
$\mathbf{1 9}$ & AEFES & -0.1296 & 0.2765 & 0.4061 \\
$\mathbf{2 0}$ & ERSU & -0.2040 & 0.2612 & 0.4651 \\
$\mathbf{2 1}$ & AVOD & -0.3466 & 0.2246 & 0.5713 \\
$\mathbf{2 2}$ & BANVT & -0.3788 & 0.2179 & 0.5967 \\
$\mathbf{2 3}$ & MERKO & -0.3833 & 0.2046 & 0.5878 \\
$\mathbf{2 4}$ & PINSU & -0.4552 & 0.1629 & 0.6181 \\
$\mathbf{2 5}$ & EKIZ & -0.5094 & 0.1244 & 0.6338 \\
$\mathbf{2 6}$ & TKURU & -0.5627 & 0.1214 & 0.6841 \\
\hline
\end{tabular}

Yöntemin altıncı aşamasında, Tablo 6'da rapor edilen pozitif ve negatif üstünlük değerleri kullanılarak hesaplanan, PROMETHEE I kısmi sıralama sonuçları Şekil 1'de yer almaktadır. Şekil 1'de görülen sol sütun pozitif üstünlük değerlerini temsil ederken sağ sütun ise negatif üstünlükleri temsil etmektedir. Burada, her iki sütunda da üst siralarda yer alan firmaların diğer firmalara göre daha baskın olduğu ifade edilebilir. 


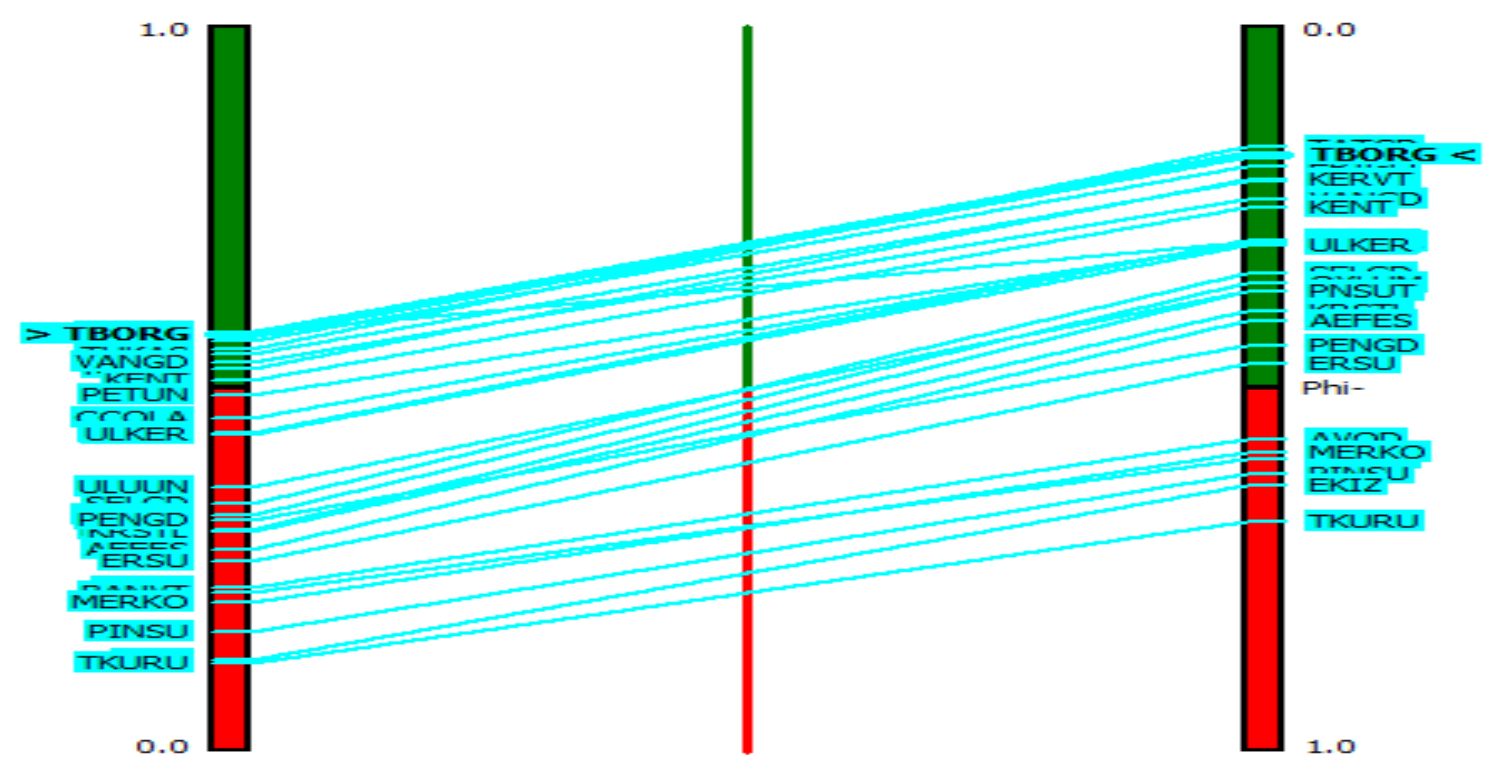

Şekil 1. PROMETHEE I Kısmi Sıralama Sonuçları (2020 Yılı İçin)

Yöntemin son aşamasında ise PROMETHEE II ile tam sıralama sonuçları tespit edilmektedir. Tespit edilen tam üstünlük değerleri hangi pay senetlerinin portföye dahil edilmesi gerektiğini göstermektedir. Buna göre 0 ile +1 değerleri arasında yer alan firmaların portföye dahil edilmesi gerekmektedir.

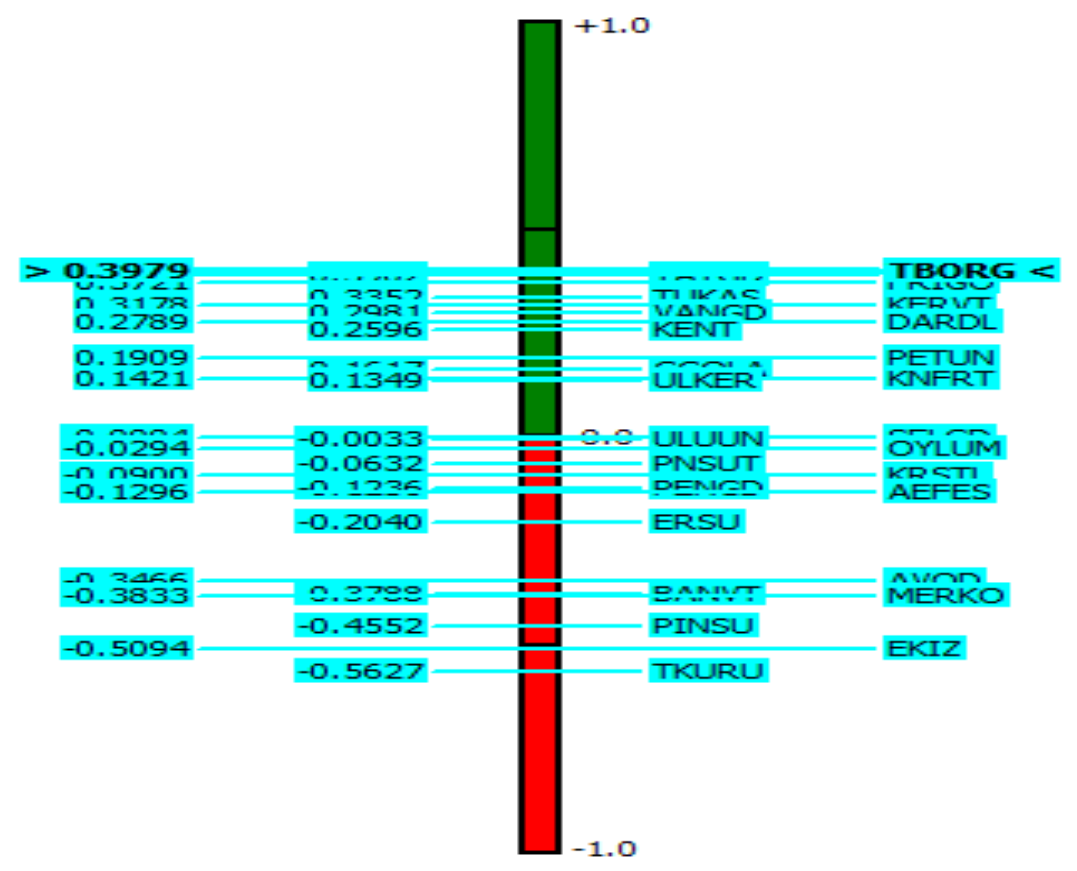

Şekil 2. PROMETHEE II Tam Sıralama Sonuçları (2020 Y11ı İçin)

Şekil 2 incelendiğinde 6 firmanın (TBORG, PETUN, CCOLA, KNFRT, ULKER ve ULUUN) 0'ın üstünde, 22 firmanın ise 0'ın altında değerlere sahip olduğu görülmektedir. Dolayısıyla oluşturulacak olan bir portföye dahil edilmesi gereken 6 firmanın olduğu ifade 
edilebilir. Tablo 7'de ise çalışma kapsamına alınan tüm dönemler için hesaplanmış olan pozitif ve negatif üstünlük değerleri rapor edilmiştir.

Tablo 7. Gıda, İçki ve Tütün Sektörü Firmalarının Pozitif ve Negatif Üstünlük

Değerleri (Tüm Yıllar İçin)

\begin{tabular}{|c|c|c|c|c|c|c|c|c|c|c|c|c|}
\hline & \multicolumn{3}{|c|}{2020} & 2019 & \multicolumn{2}{|c|}{2018} & \multicolumn{2}{|c|}{2017} & \multicolumn{2}{|c|}{2016} & \multicolumn{2}{|r|}{2015} \\
\hline Sira & Firma & Phi & Firma & Phi & Firma & Phi & Firma & Phi & Firma & Phi & Firma & Phi \\
\hline 1 & TBORG & 3979 & SELGD & 0,3796 & KNFRT & 0,4707 & KNFRT & 0,3720 & TBORG &, 2728 & TBORG & 0,2884 \\
\hline 2 & TATGD & 02 & FRIGO & 0,3107 & FRIGO & 3635 & TBORG & 0,2395 & AVOD & ,2509 & TUKAS & 0,2598 \\
\hline 3 & FRIGO & 3721 & AVOD & 0,1983 & TBORG & 2719 & BANVT & 0,2218 & KNFRT & 2346 & PETUN & 148 \\
\hline 4 & TUKAS & 0.3352 & TUKAS & 0,1543 & TUKAS & 0,2161 & ULKER & 0,2089 & TKURU & 1829 & SELGD & 1712 \\
\hline 5 & KERVT & 0.3178 & KNFRT & 0,1523 & PETUN & 0,1833 & PETUN & 0,1857 & TUKAS & 0,1502 & TATGD & 648 \\
\hline 6 & VANGD & 0.2981 & BANVT & 0,1506 & ULUUN & 0,1755 & TATGD & 0,1171 & CCOLA & 0,1450 & ERSU & 0,1511 \\
\hline 7 & DARDL & 0.2789 & ULKER & 0,1309 & ULKER & 1563 & PNSUT & 0,0929 & AEFES & 0,1168 & KNFRT & 0,1457 \\
\hline 8 & KENT & 0.2596 & CCOLA & 0,1057 & SELGD & ,0745 & FRIGO & 0,0899 & PETUN & 1104 & IVOD & 334 \\
\hline 9 & PETUN & 0.1909 & EKIZ & 0,0955 & PNSUT & ,0734 & ULUUN & 0,0872 & ULKER & 0,0907 & CCOLA & 878 \\
\hline 10 & CCOLA & 0.1617 & PETUN & & BANVT & & SELGD & 0627 & LUUN & ,0748 & NSUT & 37 \\
\hline 11 & KNF & & PEN & & KENT & & KERVT & & BANVT & & ER & \\
\hline 12 & ULK & & DAF & & CCC & & VANGD & & TATGD & & & \\
\hline 13 & EL & & TBC & 27 & $\mathbf{O Y}$ & & NT & 1 & TL & & S & \\
\hline 14 & ULI & & ULI & & ES & & CC & & PN & 74 & 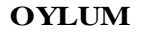 & 227 \\
\hline 15 & $\mathbf{M}$ & $-c$ & AE & -0 & $\mathbf{L}$ & -0 & TL & -0 & KO & 69 & JN & 309 \\
\hline 16 & PN & 2 & L & -0 & $D$ & 4 & $\mathbf{D}$ & -0 & $\mathbf{K E}$ & $-0,0$ & $\Gamma L$ & 578 \\
\hline 17 & KR & -0 & D & 09 & VAI & 53 & ES & -0 & SU & $-0,0962$ & JVT & 12 \\
\hline 18 & PE & -0 . & KER & 21 & U & -0 & $\mathbf{M}$ & -0 & EKIZ & $-0,1062$ & ERKO & $-0,($ \\
\hline 19 & AEI & -0 . & $\mathbf{R}$ & -0 , & AVOD & -0 & ERSU & $-0,0$ & OYLUM & $-0,1103$ & PENGD & -0 \\
\hline 20 & ERS & -0 & ENT & 289 & KRSTL & -0 & EKIZ & -0 , & SELGD & $-0,1204$ & VANGD & -0 , \\
\hline 21 & AVC & -0 . & PNs & -0 , & KERVT & -0 & TUKAS & -0 , & KERVT & $-0,1$ & FR & 31 \\
\hline 22 & BAI & -0 & VAI & -0 , & PIN & -0 & DAl & -0 & PENGD & $-0,1$ & DARDL & 53 \\
\hline 23 & ME & -0 . & TKI & 75 & MERKO & & PINSU & -0 , & DARDL & $-0,1$ & PINSU & \\
\hline 24 & PIN & -0 & OYLUM & $-0,2143$ & PENGD & -0 & TKURU & 772 & FRIGO & -0, & TKURU & 217 \\
\hline 25 & EKIZ & -0.5094 & PIN & $-0,3257$ & EKIZ & -0, & PENGD & $-0,2$ & ERSU & $-0,2395$ & KERVT & $-0,2850$ \\
\hline 26 & TKURU & -0.5627 & MERKO & $-0,3577$ & TKURU & $-0,4357$ & MERKO & $-0,3488$ & VANGD & $-0,2688$ & EKIZ & $-0,4962$ \\
\hline
\end{tabular}

Tablo 7'de yer alan sonuçlar dikkate alındığında çalışma kapsamına alınan ve 20152020 zaman aralığını kapsayan tüm dönemlerde 0 ile +1 aralığında yer alan, diğer bir ifade ile etkin sınır üzerinde yer alan 6 firmanın olduğu sonucuna ulaşılmıştır. Bu firmalar ise yukarıda bahsedildiği üzere TBORG, PETUN, CCOLA, KNFRT, ULKER ve ULUUN kodlu firmalardır. Ayrıca, söz konusu firmalar ve bu firmaların dışında kalan diğer 20 firmanın analiz kapsamına alınan dönemde pay senetlerinden elde etmiş oldukları getiriler, BIST Gıda, İçecek (XGIDA) sektörünün ve BİST-100 endeksinin aynı dönemde elde etmiş oldukları getiriler ile de karşılaştırılmıştır. Getirilere ilişkin değerler ise Tablo 8'de yer almaktadır.

Tablo 8. Getiri Karşılaştırmaları

\begin{tabular}{llll}
\hline Firma & Hisse Getiri & Endeks Getiri & BİST-100 Getiri \\
\hline TBORG & $\mathbf{1 . 9 2 4 1}$ & $\mathbf{0 . 2 4 5 0}$ & $\mathbf{0 . 7 3 7 8}$ \\
PETUN & $\mathbf{1 . 1 5 7 6}$ & $\mathbf{0 . 2 4 5 0}$ & $\mathbf{0 . 7 3 7 8}$ \\
CCOLA & $\mathbf{- 0 . 1 1 2 1}$ & $\mathbf{0 . 2 4 5 0}$ & $\mathbf{0 . 7 3 7 8}$ \\
KNFRT & $\mathbf{1 . 6 0 9 7}$ & $\mathbf{0 . 2 4 5 0}$ & $\mathbf{0 . 7 3 7 8}$ \\
ULKER & $\mathbf{0 . 4 8 6 5}$ & $\mathbf{0 . 2 4 5 0}$ & $\mathbf{0 . 7 3 7 8}$ \\
ULUUN & $\mathbf{0 . 9 8 3 8}$ & $\mathbf{0 . 2 4 5 0}$ & $\mathbf{0 . 7 3 7 8}$ \\
AEFES & 0.0773 & 0.2450 & 0.7378 \\
AVOD & -0.5665 & 0.2450 & 0.7378 \\
BANVT & -0.0604 & 0.2450 & 0.7378 \\
DARDL & -0.0684 & 0.2450 & 0.7378 \\
EKIZ & 0.1106 & 0.2450 & 0.7378
\end{tabular}




\begin{tabular}{llll} 
ERSU & 0.1508 & 0.2450 & 0.7378 \\
FRIGO & -0.9065 & 0.2450 & 0.7378 \\
KENT & -0.0070 & 0.2450 & 0.7378 \\
KERVT & 0.1356 & 0.2450 & 0.7378 \\
KRSTL & 0.1587 & 0.2450 & 0.7378 \\
MERKO & 0.0714 & 0.2450 & 0.7378 \\
OYLUM & -0.4861 & 0.2450 & 0.7378 \\
PENGD & 0.1011 & 0.2450 & 0.7378 \\
PINSU & 0.2265 & 0.2450 & 0.7378 \\
PNSUT & 0.1010 & 0.2450 & 0.7378 \\
SELGD & -0.2368 & 0.2450 & 0.7378 \\
TATGD & -0.3657 & 0.2450 & 0.7378 \\
TKURU & 0.0716 & 0.2450 & 0.7378 \\
TUKAS & -0.8463 & 0.2450 & 0.7378 \\
VANGD & 0.2402 & 0.2450 & 0.7378 \\
\hline
\end{tabular}

Tablo 8'de yer alan veriler dikkate alındığında, seçilen karar alternatifleri ve değerlendirme kriterlerine bağlı olarak tespit edilen altı firmanın beşinde firma getirisinin sektör endeksinden ve dördünde ise BİST-100 endeksinden yüksek olduğu, bir firmanın sektör ve BİST-100 endeksinden, iki firmada ise BİST100 endeksinden düşük olduğu görülmektedir. Buna ilaveten, söz konusu 2015-2019 dönemi analiz kapsamına alınan diğer 20 firmanın getiriler ise hem endeks bazındaki hem de BİST-100 bazındaki getirilerden daha düşük olarak gerçekleşmiştir. Bu sonuçlara göre genel olarak analiz sürecinde tercih edilen bütünleşik model ile belirlenen kriterlerin başarılı bir sonuç ortaya koyduğu ifade edilebilir.

\section{SONUÇ VE DEĞERLENDİRME}

Modern dönemde portföy seçimi, finansal yatırımcılar veya karar vericilerin yoğun olarak ilgilendiği ve önceden tanımlanan kısıtlar ile belirlenen hedefler doğrultusunda optimum portföy seçimi olarak ifade edilebilen, finansın önemli konularından birisidir. Portföyler, ekonomik krizlerden veya ekonomik şoklardan, politik krizlerden, finansal dalgalanmalardan ve oldukça hızlı bir şekilde gelişim gösteren teknolojiden etkilenme potansiyeline sahip birden çok pay senedinden oluşmaktadır. Yatırım kararlarının verilmesi sürecinde tasarruf sahipleri, kısıtlı fonlara sahip olmaları sebebiyle büyük bir baskı ile karşı karşıya kalabilmektedirler. Alınan yatırım kararlarının yanlış ya da isabetsiz olması durumunda arzu edilen getiriler elde edilemeyecek ve bu sonuçtan hem firmalar hem de yatırımcılar olumsuz etkileneceklerdir. Ayrıca, yatırım kararı sürecinde dikkate alınması gereken birden çok kriterinde bulunması, bu sürecin zorlaşmasına neden olacaktır. Dolayısıyla yatırım kararlarının doğru bir şekilde verilebilmesi için rasyonel karar süreçlerine başvurulmalı ve analitik yöntemler tercih edilmelidir. Söz konusu yöntemlerden biri de ÇKKV yaklaşımlarıdır. Bu yaklaşımlar, yatırım kararı sürecinde tasarruf sahiplerine optimal çözüm önerileri sunmaktadır. ÇKKV yöntemlerinden biri olan PROMETHEE yöntemi de tasarruf sahiplerine bu anlamda analitik çözümler sunan yöntemlerdendir. PROMETHEE yöntemi, çok problemli karar süreçlerinde en etkili ve en kolay çözüm önerileri sunan yöntemlerden biridir. Birden çok karar kriteri belirlenerek bu kriterlere önem düzeyine göre ağırlık katsayıları atanmakta ve karar alternatifleri arasında kolayca bir sıralama yapilabilmektedir. 
Dolayısıyla bu çalışmada, BİST’te faaliyet gösteren Gıda, İçecek ve Tütün sektörü firmalarının 2015-2020 dönemini kapsayan finansal verileri kullanılarak portföy seçim problemi için bütünleşik modeli önerilmiştir. İlk olarak, SD yönteminden faydalanılarak analiz kapsamına alınan değerlendirme kriterlerine ilişkin önem ağırlıkları tespit edilmiştir. SD yönteminden elde edilen bulgulara göre söz konusu dönemde firma performansı üzerinde etkili olan en önemli kriter çalışma kapsamına alınan tüm dönemlerde cari oran kriteridir. $\mathrm{Bu}$ sonuç likiditenin firmalar açısından faaliyetlerini yürütebilme ve firma performansını artırabilme açısından ne kadar önemli olduğunun bir göstergesidir. Buna ilaveten söz konusu dönemde firma performansı üzerinde etkisi en az olan kriterin ise yıllara göre değişkenlik gösterdiği sonucuna ulaşılmıştır.

İkinci aşamada ise SD yönteminden elde edilen kriterlere ilişkin önem ağırlıkları PROMETHEE yöntemine dahil edilerek, söz konusu firmalardan hangilerinin etkin sinır üzerinde bir değere sahip olduğu tespit edilmiştir. PROMETHEE yönteminden elde edilen bulgulara göre ise analiz kapsamına alına tüm dönemlerde etkin sınır üzerinde yer alan 6 firma tespit edilmiştir. Bu firmalar, TBORG, PETUN, CCOLA, KNFRT, ULKER ve ULUUN şeklindedir. Buradan hareketle, oluşturulacak olan bir optimal portföye bu firmaların dahil edilebileceği ifade edilebilir.

Sonuç olarak seçilen karar alternatifleri ve değerlendirme kriterleri kapsamında genel olarak analiz sürecinde tercih edilen bütünleşik model ile belirlenen kriterlerin başarılı bir sonuç ortaya koyduğu ifade edilebilir. Elde edilen sonuçlar, portföy yönetimi, portföy optimizasyonu, portföy yatırımları, yatırımlar, yatırımcılar ve yatırımcılarına etkin sınır üzerinde getiri sağlamak isteyen firmalar açısından kullanılabilirlik taşımaktadır.

Bu çalışmanın bazı kısıtları da bulunmaktadır. İlk olarak analiz kapsamında yalnızca SD yöntemine dayalı PROMETHEE yönteminin kullanılması bir kısıt olarak değerlendirilebilir. Çalışmada yalnızca 2015-2020 yıllarına ilişkin finansal verilerin kullanılması ve yalnızca tek bir sektörün analiz kapsamına alınması da birer kısıt olarak ifade edilebilir. Dolayısıyla bundan sonra yapılacak olan çalışmalarda farklı finansal göstergeler, farklı örneklemler, daha farklı bir dönem ya da dönemler seçilerek ve daha farklı ÇKKV teknikleri kullanılması literatüre katkı sağlayacaktır.

\section{KAYNAKLAR}

Ahmadzade, Masoud - Fazli, Safar - Khosroanjom, Davod - Mavi Reza Kiani (2011), "Utilizing Data Envelopment Analysis for Selecting Stockand Benchmark Firms in Tehran Stock Exchange”, International Journal of Operational Research, 12 (4), pp. $446-463$.

Aksarayl1, Mehmet - Pala, Osman. (2016), “A Hybrid Multi-Objective Optimization Approach for Portfolio Selection Problem”, In International Strategic Research Congress Proceedings Book, pp. 447-465.

Arditt1, Fred D. (1971), Another Look at Mutual Fund Performance, Journal of Financial and Quantitative Analysis, 6(03), pp. 909-912. 
Aydın, Yüksel (2020), “A Hybrid Multi-Criteria Decision Making (MCDM) Model Consisting of SD \& COPRAS Methods in Performance Evaluation of Foreign Deposit Banks”, Equinox, Journal of Economics, Business \& Political Studies, 7(2), pp. 160176.

Basso, Antonella - Funari, Stefania (2001), “A Data Envelopment Analysis Approach to Measure the Mutual Fund Performance", EuropeanJournal of Operational Research,135, pp. 477-492.

Bayramoğlu, Mehmet Fatih - Yayalar, Nagihan (2017), "Portföy Seçiminde Toplam Riski Temel Alan Portföy Performans Ölçütlerinin Değerlendirilmesi”, Bolu Abant İzzet Baysal Üniversitesi Sosyal Bilimler Enstitüsü Dergisi, 17(1), ss. 1-28.

Bedir, Neşet - Eren, Tamer (2015), “AHP-PROMETHEE Yöntemleri Entegrasyonu ile Personel Seçim Problemi: Perakende Sektöründe Bir Uygulama”, Sosyal Bilimler Araştırma Dergisi, 4(4), ss. 46-58.

Biswas, Debasish (2015), “The Effect of Portfolio Diversification Theory: Study on Modern Portfolio Theory of Stock Investment in The National Stock Exchange”, Journal of Commerce and Management Thought, 6(3), pp. 445-455.

Bouri, Abdelfettah - Martel, Jean Marc - Chabchoub, Habib (2002), "A Multi-Criterion Approach for Selecting Attractive Portfolio", Journal of Multi-Criteria Decision Analysis, 11(4-5), pp. 269-277.

Brans, Jean Pierre - Vincke, Ph (1985), "Note-A Preference Ranking Organization Method: (The PROMETHEE Method for Multiple Criteria Decision-Making)”, Management Science, 31(6), pp. 647-656.

Brans, Jean Pierre (1982), “L'ingenierie De La Decision: Elaboration D'instruments D'aide A La Decision. La Methode PROMETHEE”, Universite Laval, Colloque d'aide a la Decision, Quebec, Canada, pp. 183-213.

Chen, Hsin Hung (2008), “Stock Selection Using Data Envelopment Analysis”, Industrial Management and Data Systems, 108, pp. 1255-1268.

Dagdeviren, Metin - Eraslan, Erguen (2008), “Supplier Selection Using PROMETHEE Sequencing Method", Journal of the Faculty of Engineering and Architecture of Gazi Unıversity, 23, pp. 69-75.

Demirtaş, Özgür - Güngör Zulal (2005), “Portföy Yönetimi ve Portföy Seçimine Yönelik Uygulama”, Havacilık ve Uzay Teknolojileri Dergisi, 4, ss. 103-109.

Diakoulaki, Danae - Mavrotas, George - Papayannakis, Lefteris (1995), "Determining Objective Weights in Multiple Criteria Problems: The Critic Method”, Computers \& Operations Research, 22(7), pp. 763-770. 
Edirisinghe, N. Chanaka - Zhang Xin (2008), "Portfolio Selection under DEA-Based Relative Financial Strength Indicators: Case of US Industries”, Journal of the Research Society. 59, pp. 842-856.

Eilat, Harel - Golany Boaz - Shtub Avraham (2006), “Constructing and Evaluating Balanced Portfolios of R\&D with Interactions: A DEA Based Methodology”, European Journal of Operational Research. 172, pp. 1018-1039.

Emel, Ahmet Burak - Oral Metin - Reisman Arnold- Yolalan Reha (2003), “A Credit Scoring Approach for The Commercial Banking Sector”, Socio-Economic Planning Sciences, 37, pp. 103-123.

Grujić, Miloš (2016), “Application of The Modern Portfolio Theory in Diversification of The Debt Securities Portfolio in Emerging Markets”, Zbornik Radova Ekonomskog Fakulteta U Istočnom Sarajevu, (13), pp. 67-80.

Ishizaka, Alessio - Nemery, Philippe (2011), "Selecting the Best Statistical Distribution with PROMETHEE and GAIA”, Computers \& Industrial Engineering, 61(4), pp. 958-969.

Işık, Özcan - Koşaroğlu, Merve Şerife (2020), "Analysis of the Financial Performance of Turkish Listed Oil Companies Through the Application of SD and MAUT Methods", Üçüncü Sektör Sosyal Ekonomi Dergisi, 55(3), ss. 1395- 1411.

Işık, Özcan. (2020), "SD Tabanlı MABAC ve WASPAS Yöntemleriyle Kamu Sermayeli Kalkınma ve Yatırım Bankalarının Performans Analizi”, Uluslararası İktisadi ve İdari İncelemeler Dergisi, (29), ss. 61-78.

Jahan, Ali - Mustapha, Faizal - Sapuan, S. M - Ismail, Md Yusof - Bahraminasab, Marjan (2012), “A Framework for Weighting of Criteria in Ranking Stage of Material Selection Process”, The International Journal of Advanced Manufacturing Technology, 58(1-4), pp. 411-420.

Janani, Mohammad Hasan - Ehsanifar, Mohammad - Bakhtiarnezhad, Sanam (2012), "Selection of Portfolio by Using Multi Attributed Decision Making (Tehran Stock Exchange)”, American Journal of Scientific Research, 44(2), pp. 15-29.

Kartal, Cem (2019), "MOORA Metodu ile Portföy Yönetimi Geleneksel Yöntemlere ve Şans Faktörüne Dayalı Portföylerle Bir Karşılaştırma Uygulaması”, Maliye ve Finans Yazıları, (111), ss. 299-318.

Kayalıdere, Koray - Aktaş, Hüseyin (2008), “Alternatif Portföy Seçim Modellerinin Performanslarının Karşılaştırılması (İMKB örneği)”, Dokuz Eylül Üniversitesi Sosyal Bilimler Enstitüsü Dergisi, 10(1), ss. 290-312.

Konno, Hiroshi - Shırakawa, Hiroshi - Yamazak1, Hiroaki (1993), “A Mean-Absolute Deviation-Skewness Portfolio Optimization Model”, Annals of Operations Research, 45(1), pp. 205-220. 
Korkmaz, Turhan - Pekkaya, Mehmet. (2012), Excel Uygulamalı Finans Matematiği, Cilt:1, Ekin Basım Yayın Dağıtım, Ankara.

Küçükkocaoğlu, Güray (2002), “Optimal Portföyün Seçimi ve İMKB Ulusal-30 Endeksi Üzerine Bir Uygulama”, Active-Bankacılık ve Finans Dergisi, 26, ss. 74-91.

Lim, Sungmook - Oh, Wuk - Zhu, Joe (2014), "Use of DEA Cross-Efficiency Evaluation in Portfolio Selection: An Application to Korean Stock Market”, European Journal of Operational Research, 236(1), pp. 361-368.

Marasović, Branka - Babić, Zoran (2011), “Two-Step Multi-Criteria Model for Selecting Optimal Portfolio”, International Journal of Production Economics, 134(1), pp. 58-66.

Markowitz, Harry Max (1952), "Portfolio Selection”, The Journal of finance, 7(1), pp. 77-91.

Markowitz, Harry Max (1999), “The Early History of Portfolio Theory: 1600-1960”, Financial Analysis Journal, 55(4), pp. 5-16.

Murthi B. S - Choi Yoon K. - Desai Preyas (1997), "Efficiency of Mutual Funds and Portfolio Performance Measurement: A non-Parametric Approach”, European Journal of Operational Research, 98, pp. 408-418.

Nielsen, Lars Tyge (1987), "Portfolio Selection in the Mean-Variance Model: A Note", Journal of Finance, 42 (5), pp. 1371-1376.

Özdemir, Mehmet Hakan (2016), “Entropi Optimizasyonu Yöntemiyle Portföy Seçimi”, İstanbul Üniversitesi İşletme Fakültesi İşletme İktisadı Enstitüsü Yönetim Dergisi, 27(81), ss. 43-57.

Pala, Osman - Aksarayl1, Mehmet (2017), "BIST-30 Endeksinde Entropi ve Yüksek Momentlerle TOPSIS ve PROMETHEE Tabanlı Çok Amaçlı Portföy Seçimi Modeli Önerisi”, Adnan Menderes Üniversitesi Sosyal Bilimler Enstitüsü Dergisi, 4(4), ss. 171-188.

Pätäri, Eero - Karell, Ville - Luukka, Pasi - Yeomans, Julian S. (2018), “Comparison of The Multicriteria Decision-Making Methods for Equity Portfolio Selection: The US Evidence”, European Journal of Operational Research, 265(2), pp. 655-672.

Roy Andrew Donald D. (1952), "Safety First and Holding of Assets”, Econometrica, 20(3), pp. 431-449.

Şahin, Ayşegül - Akkaya, Cenk G. (2013), "PROMETHEE Sıralama Yöntemi ile Portföy Oluşturma Üzerine Bir Uygulama", Ekonomi ve Yönetim Araştırmaları Dergisi, 2(2), ss. 67-81.

Sarıkaya, Görkem - Tatlidil, Hüseyin (2014), "Entropi Optimizasyon Ölçüsü ile Optimal Portföy Seçimi ve BİST Ulusal-30 Endeksi Üzerine Bir Çalışma”, Dumlupınar Üniversitesi Sosyal Bilimler Dergisi, ss. 381-402. 
Söylemez, Esra Yıldırım - Koç Yasemin Deniz (2017), "Çok Kriterli Karar Verme Yöntemleri ile Optimal Portföy Seçimi: Borsa İstanbul Örneği”, Uşak Üniversitesi Sosyal Bilimler Dergisi, 10(IASOS Özel Sayısı-), ss. 117-133.

Tekin, Bilgehan - Güçlü, Pembe- Keskin, Burak (2019), "Pay Senetlerinden Portföy Oluşturmaya Bulanık Kümeleme Analizi Yaklaşımı: BIST 100 Endeksi Pay Senetleri Üzerine Bir Uygulama”, Ankara Hacı Bayram Veli Üniversitesi İktisadi ve İdari Bilimler Fakültesi Dergisi, 21(2), ss. 238-262.

Tiryaki, Fatma (2001), "The Use of Data Envelopment Analysis for Stock Selection on Istanbul Stock Exchange”, İstanbul Üniversitesi İşletme Fakültesi Dergisi, 30(2), ss. 29-51.

Vetschera, Rudolf - De Almeida, Adiel Teixeira (2012), “A PROMETHEE-Based Approach To Portfolio Selection Problems”, Computers \& Operations Research, 39(5), pp. 10101020. 